\title{
AIDS-Related Kaposi Sarcoma T1 (Poor Risk): Edema or Ulceration
}

National Cancer Institute

\section{Source}

National Cancer Institute. AIDS-Related Kaposi Sarcoma T1 (Poor Risk): Edema or

Ulceration. NCI Thesaurus. Code C134973.

AIDS-related Kaposi sarcoma with edema or ulceration due to the tumor. 